\title{
Impact of insurance and supply of health professionals on coverage of treatment for hypertension in Mexico: population based study
}

\author{
Sara N Bleich, assistant professor, ${ }^{1}$ David M Cutler, dean of social sciences, ${ }^{2}$ Alyce S Adams, assistant \\ professor, ${ }^{3}$ Rafael Lozano, director general of information, ${ }^{4}$ Christopher J L Murray, director ${ }^{5}$
}

Jjohns Hopkins School of Public Health, Baltimore, MD 21205, USA

${ }^{2}$ Harvard University Faculty of Arts and Sciences, Cambridge, MA

${ }^{3}$ Harvard Medical School and Harvard Pilgrim Health Care, Boston, MA

${ }^{4}$ Secretaría de Salud, Mexico DF, Mexico

${ }^{5}$ Institute of Health Metrics and Evaluation, University of Washington, Seattle, WA

Correspondence to: S N Bleich sbleich@jhsph.edu

doi:10.1136/bmj.39350.617616.BE

\section{ABSTRACT}

Objective To examine the independent and combined contributions of insurance status and supply of health professionals on coverage of antihypertensive treatment among adults in Mexico.

Design Population based study.

Setting Mexico.

Participants 4032 hypertensive adults (2967 uninsured and 1065 insured): 1065 uninsured adults matched with 1065 adults insured through Seguro Popular, a programme to expand health insurance coverage to uninsured people in Mexico.

Main outcome measures Coverage of antihypertensive treatment and coverage of antihypertensive treatment with control of blood pressure.

Results Rates of treatment for hypertension varied by insurance status and supply of health professionals. Hypertensive adults insured through Seguro Popular had a significantly higher probability of receiving antihypertensive treatment (odds ratio 1.50, 95\% confidence interval 1.27 to 1.78 ) and receiving antihypertensive treatment with control of blood pressure $(1.35,1.00$ to 1.82$)$. Greater supply of health professionals in areas with coverage through Seguro Popular was a significant predictor of antihypertensive treatment after adjusting for covariates $(1.49,1.00$ to 2.20$)$.

Conclusions Expansion of healthcare coverage to uninsured people in Mexico was associated with greater use of antihypertensive treatment and blood pressure control, particularly in areas with a greater supply of health professionals.

\section{INTRODUCTION}

Hypertension affects more than 9 million adults in Mexico and is expected to increase with rising rates of obesity. ${ }^{1}$ Hypertension greatly increases the risk of cardiovascular diseases such as ischaemic heart disease (the second leading cause of death in Mexico) and stroke (the third leading cause of death in Mexico). ${ }^{2-4}$ This year Mexico expects to spend \$3bn (£1.5bn; $€ 2 \mathrm{bn}$ ) on treating hypertension alone. ${ }^{5}$ Studies have shown that reductions in blood pressure significantly reduce the incidence of and mortality from cardiovascular disease. ${ }^{6-8}$ Despite the availability of effective drugs, treatment is suboptimal and varies by region in Mexico. ${ }^{910}$

Lack of health insurance has been consistently identified as a key obstacle to antihypertensive treatment ${ }^{11-15}$ and to the use of healthcare services more generally. ${ }^{16}$ Mexico's recently implemented Seguro Popular programme, which by 2010 will legally extend health insurance to all uninsured people (about 50 million people), has the potential to increase access to treatment for hypertension, and potentially improve health outcomes. The insurance package covers 249 interventions, including diagnosis and treatment of hypertension. ${ }^{17}$ These services are universally accessible to people insured through the programme. The law, however, stipulates that priority for affiliation is to be given to poor households in areas characterised by high deprivation, as well as to people living in rural areas and indigenous groups. ${ }^{18}$ Affiliation with Seguro Popular is also encouraged among those families identified as having higher expected healthcare costs. Therefore the bulk of current enrollees belong to the bottom three tenths for income. ${ }^{19}$ In addition, Seguro Popular was designed to start in communities where health facilities were sufficiently equipped to provide the services included in the insurance package. ${ }^{18}$ In low income and rural areas, supply related factors may impede the effectiveness of the programme in increasing access to antihypertensive treatment.

Recent research exploring the impact of Seguro Popular indicates that it is having a positive effect. Inequalities in public health expenditure and treatment coverage across states have narrowed, the use of healthcare services has increased for insured compared with uninsured people, catastrophic expenditure has decreased for insured compared with uninsured people, and federal expenditure on health has increased..$^{19}$

We assessed whether Seguro Popular is sufficient to increase coverage of antihypertensive treatment or whether it has a greater effect in areas with a higher supply of health professionals. We also determined the independent effect of health professional supply on the insurance programme. Inadequate supply of health providers has been linked to poor health 
outcomes. ${ }^{20-27}$ For example, in the United States those states with higher physician to population ratios have lower rates of all cause mortality. ${ }^{28}$ The inclusion of heath professional supply in this analysis is also important given that the roll-out of Seguro Popular is not random, making it harder to isolate the independent effect of the insurance programme.

We examined the association between Seguro Popular and coverage of antihypertensive treatment and control of blood pressure among hypertensive adults. Coverage was defined as the fraction of those who

Table 1 | Sociodemographic characteristics of hypertensive adults by insurance type. Data from Mexico national health and nutrition survey, 2005. ${ }^{36}$ Values are numbers (percentages) unless stated otherwise

\begin{tabular}{|c|c|c|c|c|}
\hline \multirow[b]{2}{*}{ Characteristic } & \multirow[b]{2}{*}{$\begin{array}{l}\text { All social security } \\
\qquad(n=3403)\end{array}$} & \multicolumn{2}{|c|}{ Study population } & \multirow[b]{2}{*}{$\begin{array}{l}P \text { value } \\
\left.\text { ( } X^{2} \text { test }\right)\end{array}$} \\
\hline & & $\begin{array}{l}\text { Insured through } \\
\text { Seguro Popular } \\
\quad(n=1065)\end{array}$ & $\begin{array}{l}\text { Uninsured } \\
(n=2967)\end{array}$ & \\
\hline Men & $1365(40.1)$ & $390(36.6)$ & $1171(39.5)$ & 0.102 \\
\hline Women & $2038(59.9)$ & $675(63.4)$ & $1796(60.5)$ & \\
\hline \multicolumn{5}{|l|}{ Age (years): } \\
\hline $20-39$ & $394(11.6)$ & $178(16.7)$ & $490(16.5)$ & \multirow[t]{4}{*}{0.009} \\
\hline $40-59$ & 1290 (37.9) & $461(43.3)$ & $1192(40.2)$ & \\
\hline $60-79$ & $1476(43.4)$ & $371(34.8)$ & $1042(35.1)$ & \\
\hline$\geq 80$ & $243(7.1)$ & $55(5.2)$ & $243(8.2)$ & \\
\hline \multicolumn{5}{|l|}{ Permanent income*: } \\
\hline 1st fifth & $266(7.9)$ & $368(34.6)$ & $844(28.5)$ & \multirow[t]{5}{*}{$<0.001$} \\
\hline 2nd fifth & $499(14.8)$ & $308(28.9)$ & $716(24.1)$ & \\
\hline 3rd fifth & 665 (19.7) & $199(18.7)$ & $521(17.6)$ & \\
\hline 4th fifth & $930(27.6)$ & $141(13.2)$ & $533(18.0)$ & \\
\hline 5th fifth & $1016(30.1)$ & $49(4.6)$ & 353 (11.9) & \\
\hline \multicolumn{5}{|l|}{ Marginality indext: } \\
\hline 1st fifth & $299(8.8)$ & $331(31.1)$ & $828(27.9)$ & \multirow[t]{5}{*}{$<0.001$} \\
\hline 2nd fifth & $670(19.7)$ & $407(38.2)$ & $820(27.6)$ & \\
\hline 3rd fifth & $771(22.7)$ & $203(19.1)$ & $536(19.0)$ & \\
\hline 4th fifth & $906(26.6)$ & $70(6.6)$ & $467(15.7)$ & \\
\hline 5th fifth & $757(22.3)$ & $54(5.1)$ & $289(9.7)$ & \\
\hline \multicolumn{5}{|l|}{ Area of residence: } \\
\hline Urban & $2970(87.3)$ & $534(50.1)$ & $1930(65.0)$ & \multirow[t]{2}{*}{$<0.001$} \\
\hline Rural & $433(12.7)$ & $531(49.9)$ & $1037(35.0)$ & \\
\hline \multicolumn{5}{|l|}{ Region: } \\
\hline Border & $872(25.6)$ & $151(14.2)$ & $405(13.7)$ & \multirow[t]{5}{*}{$<0.001$} \\
\hline North & $796(23.4)$ & $238(22.4)$ & $648(21.8)$ & \\
\hline Central & $813(23.9)$ & $355(33.3)$ & $844(28.5)$ & \\
\hline Mexico City & $219(6.4)$ & $15(1.4)$ & $148(5.0)$ & \\
\hline South & $703(20.7)$ & $306(28.7)$ & $922(31.1)$ & \\
\hline Not indigenous & $2876(84.7)$ & $831(78.0)$ & $2247(75.7)$ & \multirow[t]{2}{*}{0.131} \\
\hline Indigenous & $521(15.3)$ & $234(22.0)$ & $720(24.3)$ & \\
\hline Non-indigenous language & $3250(95.5)$ & $965(90.6)$ & $2676(90.2)$ & \multirow[t]{2}{*}{0.692} \\
\hline Indigenous language & $152(4.5)$ & $100(9.4)$ & $291(9.8)$ & \\
\hline \multicolumn{5}{|l|}{ Education: } \\
\hline None or preschool & $390(11.5)$ & $267(25.1)$ & $722(24.3)$ & \multirow[t]{4}{*}{$<0.001$} \\
\hline Primary & $1819(53.7)$ & $644(60.5)$ & $1619(54.6)$ & \\
\hline Secondary & $619(18.3)$ & $128(12.0)$ & $402(13.6)$ & \\
\hline Higher education & $558(16.5)$ & $26(2.4)$ & $224(7.6)$ & \\
\hline
\end{tabular}

Numbers may not add to $100 \%$ because of rounding. Data are unweighted.

*From poorest (1st fifth) to richest (5th fifth).

†From most marginalised (1st fifth) to least marginalised (5th fifth). needed treatment who used it..$^{9}$ We also explored whether the supply of health professionals (number of doctors and number of nurses per 1000 population) was a mediating or moderating factor in the relation between Seguro Popular and antihypertensive treatment and blood pressure control. We hypothesised that Seguro Popular would be a significant predictor of coverage for both. We further hypothesised that Seguro Popular would affect the care of hypertension differentially on the basis of the level of health provider supply.

Mexico has a national programme for hypertension - focusing on the entire population - that aims to increase detection and treatment, provide medical education, and train healthcare professionals. ${ }^{29}$ People without insurance are able to purchase antihypertensive drugs through the programme, and doctors who prescribe may receive a nominal payment. Given that the primary focus of the programme is detection, it is unlikely that it would significantly affect our ability to isolate the effect of Seguro Popular on coverage of antihypertensive treatment.

\section{METHODS}

The study population consisted of respondents to the 2005 Mexican national health and nutrition survey ${ }^{30}$ who had hypertension, were aged 20 or more, and were eligible for insurance coverage through Seguro Popular $(\mathrm{n}=4032)$. The response rates for the survey were $97 \%$ for households, $96 \%$ for individual adults within participating households, and 70\% for blood pressure measurement among participants. We considered participants to be hypertensive if the average of two systolic blood pressure readings (taken five minutes apart) was $140 \mathrm{~mm} \mathrm{Hg}$ or higher or if participants reported currently using antihypertensives. ${ }^{831}$ The survey was designed to collect blood pressure measurements for the entire sample. We considered participants to be eligible for Seguro Popular if they were uninsured or already affiliated with the insurance scheme. For comparison we included hypertensive people with social security, but we excluded them from the propensity score analysis.

We obtained measures of health professional supply (number of doctors and number of nurses) from the 2005 Mexican National Registry of Health Infrastructure $(\mathrm{n}=12566)$, a database that includes human resources for ministry of health facilities. ${ }^{32}$ Almost all public facilities (98\%) completed the infrastructure survey. To determine the number of doctors and nurses per 1000 population we obtained the total population numbers for each municipality from the population census produced by the National Population Council. Overall, $2.6 \%$ of contacted households failed to complete the questionnaire; 24.7 million households were included in the census.

\section{Measures}

Outcomes

We used two outcome variables in this analysis: coverage of antihypertensive treatment and coverage of 
antihypertensive treatment with control of blood pressure. Participants were considered to be receiving treatment if they answered "yes" to the survey question "Are you currently taking medication to control your high blood pressure?" Participants were considered to have controlled hypertension if they reported taking antihypertensives and their average systolic blood pressure was $120 \mathrm{~mm} \mathrm{Hg}$ or less. We used $120 \mathrm{~mm}$ $\mathrm{Hg}$ as the threshold for control on the basis of the optimum recommended target from the American Heart Association. ${ }^{8}$ Given that this threshold is more rigorous than the standard definition we also included

Table 2 | Sociodemographic characteristics of study population matched by propensity. * Data from Mexico national health and nutrition survey, 2005. ${ }^{36}$ Values are numbers (percentages) unless stated otherwise

\begin{tabular}{|c|c|c|c|}
\hline Characteristic & $\begin{array}{l}\text { Insured with Seguro } \\
\text { Popular }(n=1065)\end{array}$ & $\begin{array}{l}\text { Uninsured } \\
(n=1065)\end{array}$ & $P$ value ( $X^{2}$ test) \\
\hline Male & $390(36.6)$ & $400(37.6)$ & 0.654 \\
\hline Female & $675(63.4)$ & $665(62.4)$ & \\
\hline \multicolumn{4}{|l|}{ Age (years): } \\
\hline $20-39$ & $178(16.7)$ & $180(16.9)$ & \multirow[t]{4}{*}{0.725} \\
\hline $40-59$ & $461(43.3)$ & $483(45.4)$ & \\
\hline $60-79$ & $371(34.8)$ & 353 (33.2) & \\
\hline$\geq 80$ & $55(5.2)$ & $49(4.6)$ & \\
\hline \multicolumn{4}{|l|}{ Permanent income†: } \\
\hline 1st fifth & $368(34.6)$ & $384(36.1)$ & \multirow[t]{5}{*}{0.667} \\
\hline 2nd fifth & 308 (28.9) & $304(28.5)$ & \\
\hline 3rd fifth & $199(18.7)$ & $196(18.4)$ & \\
\hline 4th fifth & $141(13.2)$ & $123(11.6)$ & \\
\hline 5th fifth & $49(4.6)$ & $58(5.5)$ & \\
\hline \multicolumn{4}{|l|}{ Marginality indexł: } \\
\hline 1st fifth & 331 (31.1) & $328(30.8)$ & \multirow[t]{5}{*}{0.981} \\
\hline 2nd fifth & $407(38.2)$ & $409(38.4)$ & \\
\hline 3rd fifth & 203 (19.1) & 198 (18.6) & \\
\hline 4th fifth & $70(6.6)$ & 77 (7.2) & \\
\hline 5th fifth & $54(5.1)$ & $53(5.0)$ & \\
\hline \multicolumn{4}{|l|}{ Area: } \\
\hline Urban & $534(50.1)$ & $548(51.5)$ & \multirow[t]{2}{*}{0.544} \\
\hline Rural & 531 (49.9) & 517 (48.5) & \\
\hline \multicolumn{4}{|l|}{ Region: } \\
\hline Border & $151(14.2)$ & $136(12.8)$ & \multirow[t]{5}{*}{0.850} \\
\hline North & $238(22.4)$ & 254 (23.9) & \\
\hline Central & $355(33.3)$ & $352(33.1)$ & \\
\hline Mexico City & $15(1.4)$ & $14(1.3)$ & \\
\hline South & $306(28.7)$ & 309 (29.0) & \\
\hline Not indigenous & $831(78.0)$ & $832(78.1)$ & \multirow[t]{2}{*}{0.958} \\
\hline Indigenous & $234(22.0)$ & 233 (21.9) & \\
\hline Non-indigenous language & $965(90.6)$ & $958(90.0)$ & \multirow[t]{2}{*}{0.609} \\
\hline Indigenous language & $100(9.4)$ & $107(10.1)$ & \\
\hline \multicolumn{4}{|l|}{ Education: } \\
\hline None or preschool & $267(25.1)$ & $264(24.8)$ & \multirow[t]{4}{*}{0.695} \\
\hline Primary & $644(60.5)$ & $664(62.4)$ & \\
\hline Secondary & $128(12.0)$ & $116(10.9)$ & \\
\hline Higher & $26(2.4)$ & $21(2.0)$ & \\
\hline
\end{tabular}

*People insured with Seguro Popular were matched to uninsured people using nearest neighbour algorithm. Analytical cohort included 1065 matched pairs. All people insured with Seguro Popular were matched with someone without insurance. Data are unweighted.

†From poorest (1st fifth) to richest (5th fifth).

‡From most marginalised (1st fifth) to least marginalised (5th fifth). results for blood pressure control defined as less than $140 \mathrm{~mm} \mathrm{Hg}$.

\section{Independent variables}

The primary independent variables of interest were self reported insurance type (Seguro Popular $v$ uninsured) and number of doctors and nurses per 1000 population. Health professional supply represents access and availability of primary healthcare services in Mexico. Given that our measures of the number of doctors and number of nurses per 1000 population were highly correlated it was natural to combine them. In our combined measure we included in the primary analysis only doctors classified under general or internal medicine and nurses classified as generalists. However, we also describe the results of supplementary analyses that included all doctors and nurses.

\section{Statistical analysis}

Using propensity scores to control for selection bias ${ }^{33}$ we matched adults insured through Seguro Popular with uninsured adults using a nearest neighbour approach. The analytical cohort included 1065 matched pairs. We used logistic regression to estimate the propensity to have insurance through Seguro Popular. Participants were matched on characteristics that predicted coverage of Seguro Popular: sex, age (categorical), permanent income, marginality index, rural area, region, indigenous status, indigenous language, and education.

The marginality index is based on seven characteristics in the community: percentage of the population aged more than 15 years who are illiterate, percentage of the population aged more than 15 years who have not completed primary school, percentage of people in homes without electricity, percentage of people in homes without water connected to the public network, percentage of people in homes without plumbing or a toilet, percentage of people in homes with an earth floor, and percentage of population in localities with fewer than 5000 people. A higher value means less marginalisation. ${ }^{19}$ The marginality index is generated by the Mexico National Council on Population from the census and includes nine variables. The 2005 marginality index was not available for this analysis. Given that the seven and nine variable marginality indices from 2000 have been shown to be highly correlated $(r 0.98),{ }^{19}$ we expect that the 2005 indices should also be closely associated.

Using the matched data we carried out a multivariate analysis to estimate the independent effect of insurance status and health professional supply on coverage of antihypertensive treatment and of antihypertensive treatment with blood pressure control. Given that the supply related data were only available at the municipality level we used multivariate analysis with clustering for the supply portion of the analysis. We ran the supply related models with and without interaction terms between Seguro Popular and the number of doctors and nurses per 1000 population to test whether the impact of the insurance programme varied by provider 
supply. The inclusion of the interaction terms was assessed using the likelihood ratio test.

Statistical analyses were carried out using Stata version 9.2 and R version 2.4.1 (R Project for Statistical Computing, Vienna, Austria). The predicted probabilities from the logistic regressions were estimated using Clarify, a post-estimation program in Stata. ${ }^{34}$

\section{RESULTS}

Overall, 4032 hypertensive adults in the study population were uninsured or had insurance coverage through Seguro Popular. Table 1 presents the characteristics for the unmatched study population, compared with respondents to the Mexican national health and nutrition survey who had hypertension and some form of social security. Social security provides health insurance for formally employed people and their families (about 50 million), and includes several institutions, the largest of which is the Mexican Social Security Institute and the second largest the Insituto de Seuridad y Servicos Sociales de los Trababajadores del Estado. The Mexican Social Security Institute serves private employees and the Insituto de Seuridad y Servicos Sociales de los Trababajadores del Estado serves government employees. Compared with the eligible population insured through Seguro Popular, people with social security were older, had higher incomes, were less marginalised, lived in urban areas, were less indigenous, and were more educated.

People with insurance through Seguro Popular were more likely to be young, poor, marginalised, living in rural areas, living in the central region, and less educated than those uninsured. These differences are largely consistent with the preferential roll-out of Seguro Popular, which aimed to prioritise people in the bottom tenths for income, those in highly deprived areas, those living in rural areas, and indigenous populations. ${ }^{18}$ Controlling for the propensity score resulted in statistically significant reductions in these differences (table 2).

Table 3 summarises the unadjusted and adjusted percentages for each outcome variable: coverage of antihypertensive treatment and coverage of antihypertensive treatment with control of blood pressure.

Table 3 Predicted probabilities of receiving treatment for and control of hypertension among Mexican adults (adjusted and unadjusted). Values are percentages ( $95 \%$ confidence intervals). Data from Mexico national health and nutrition survey, $2005^{36}$

\begin{tabular}{lccc}
$\begin{array}{l}\text { Variable } \\
\text { Unadjusted*: }\end{array}$ & All social security & Insured with Seguro Popular & Uninsured \\
\hline Treatment & $63.1(60.6$ to 65.3$)$ & $50.8(47.9$ to 53.5$)$ & $43.7(41.8$ to 45.6$)$ \\
\hline Controlt & $10.3(9.3$ to 11.6$)$ & $10.3(8.9$ to 11.8$)$ & $8.3(7.3$ to 9.3$)$ \\
\hline Adjustedf: & & & \\
\hline Treatment & - & $50.7(47.7$ to 53.4$)$ & $40.7(37.7$ to 43.7$)$ \\
\hline Controlt & - & $10.2(8.8$ to 11.6$)$ & $7.8(6.3$ to 9.4$)$ \\
\hline
\end{tabular}

Data are unweighted. "All social security" group not included in propensity score analysis; presented for comparison.

*Unmatched sample.

†Among all adults with hypertension.

‡Propensity matched sample.
The unadjusted percentages refer to the unmatched sample and the adjusted percentages refer to the propensity matched sample. People with social security had a higher probability of receiving antihypertensive treatment $(60.3 \%, 95 \%$ confidence interval $60.6 \%$ to $65.3 \%$ ) but the same probability of receiving antihypertensive treatment with blood pressure control as the population insured through Seguro Popular $(10.3 \%, 9.3 \%$ to $11.6 \%)$.

Compared with uninsured adults, those insured through Seguro Popular had higher rates of coverage for antihypertensive treatment and coverage for antihypertensive treatment with blood pressure control both before and after adjustment for propensity (table 3). The rates of coverage for both outcomes were similar after adjustment-for example, of adults with hypertension in the unadjusted sample, half (50.8\%, 95\% confidence interval $47.9 \%$ to $53.5 \%)$ of those insured through Seguro Popular received antihypertensive treatment compared with $40 \%$ (43.7\%, $41.8 \%$ to $45.6 \%$ ) of those uninsured. Similarly, in the propensity matched sample, half $(50.7 \%, 47.7 \%$ to $53.4 \%$ ) of those insured through Seguro Popular received antihypertensive treatment compared with $40 \%(40.7 \%, 37.7 \%$ to $43.7 \%)$ of those uninsured. Also in the propensity matched sample, among people with an average of two systolic blood pressure measurements less than $140 \mathrm{~mm} \mathrm{Hg}$ (not shown), hypertension was controlled in a quarter of those insured through Seguro Popular (24.1\%, 21.9\% to 26.1\%) and a fifth of those uninsured $(19.3 \%, 17.2 \%$ to $21.6 \%)$.

\section{Effect of insurance on coverage of antihypertensive} treatment

Having insurance through Seguro Popular was positively and significantly associated with receiving antihypertensive treatment. The odds of those insured through Seguro Popular receiving antihypertensive treatment was $50 \%$ higher than those uninsured (odds ratio $1.50,95 \%$ confidence interval 1.27 to 1.78 ).

The magnitude of the effect was slightly smaller for those adults receiving antihypertensive treatment with blood pressure control. The odds of those insured through Seguro Popular receiving antihypertensive treatment with blood pressure control was 35\% higher than those uninsured (1.35, 1.00 to 1.82). Rates of control among those who received treatment showed a similar effect to Seguro Popular, but it was not significant possibly owing to the small sample size. In addition, Seguro Popular showed a positive and significant effect on controlled hypertension, defined as blood pressure less than $140 \mathrm{~mm} \mathrm{Hg}$.

\section{Effect of doctor and nursing supply on coverage of antihypertensive treatment}

In the model relating the number of doctors and nurses per 1000 population to antihypertensive treatment, after adjusting for insurance type, the odds ratio was not significant $(1.04,0.85$ to 1.26$)$. Results did, however, indicate a significant interaction between insurance through Seguro Popular and supply of health 
professionals. People insured through Seguro Popular and living in areas with more doctors and nurses per 1000 population had significantly higher odds of receiving antihypertensive treatment than those uninsured and living in areas with fewer doctors and nurses (odds ratio $1.49,1.00$ to 2.20 ).

In the model relating the number of doctors and nurses per 1000 population to antihypertensive treatment with control of blood pressure, after adjusting for insurance type, the odds ratio was not significant $(0.81$, 0.61 to 1.09$)$. Although the odds ratio was not significant in the model relating the interaction between Seguro Popular and supply of health professionals to coverage of antihypertensive treatment with blood pressure control, the effect size was similar to that for the treatment coverage interaction (odds ratio 1.44, 0.87 to 2.39 ). In another model (not shown) the impact of health professional supply on rates of blood pressure control among only those treated showed a similar effect size to the model relating the number of doctors and nurses per 1000 population to antihypertensive treatment. No significant odds ratio was found when examining the effect of health professional supply on controlled hypertension, defined as blood pressure less than $140 \mathrm{~mm} \mathrm{Hg}$.

The measure of health professional supply included only doctors classified under general or internal medicine and nurses classified as generalists. Given that other types of physicians and nurses may provide services for the hypertensive population, the effect of all types of health professional supply on the two outcome variables was examined and showed similar effects (not shown).

\section{DISCUSSION}

Our findings suggest that being insured through Seguro Popular - a programme to expand health insurance to all uninsured households in Mexico-is associated with higher rates of treatment for hypertension and control of blood pressure than being uninsured. Furthermore, Seguro Popular may be most effective in areas with a high ratio of health professionals to patients.

Seguro Popular is expected to increase the mean allocation of public resources for health services for each family from $\$ 268$ in 2001 (relative to a mean household consumption expenditure of \$4032) to $\$ 677$ in $2010 .^{3536}$ Secondary prevention of cardiovascular disease as a result of higher rates of treatment and control may offset the costs of expanded coverage. In 2005, almost a sixth of adults in Mexico (about 5 million people) eligible for insurance through Seguro Popular had hypertension.

Similarities and differences exist between our findings and those of previous research. The rate of antihypertensive treatment in Mexico $(45.7 \%)$ is comparable to that of the United States (58.4\%), but the rate of controlled hypertension in Mexico (8.9\%) is significantly lower than that of the United States $(31.0 \%) \cdot{ }^{37}$ Our results concur with published research showing the positive impact of Seguro Popular ${ }^{19}$ as well as studies indicating a strong relation between insurance status and treatment coverage. ${ }^{212-15}$

Seguro Popular was designed to start in communities where health facilities were sufficiently equipped to provide the services included in the insurance package. We found that Seguro Popular seems to be having the biggest impact in these communities. This finding is also consistent with a vast body of research associating positive health outcomes with supply of health professionals. ${ }^{20-27}$ Unlike previous studies our results do not indicate an independent effect of health professional supply on treatment of hypertension. This could be because variation in supply related factors is insufficient to capture an effect in those areas with high affiliation with Seguro Popular. It is also likely that insurance coverage has a more direct relation to antihypertensive treatment in Mexico than does supply of physicians or nurses. That we found a positive and significant relation between Seguro Popular and the supply of health professionals on coverage of antihypertensive treatment suggests that insurance alone is not sufficient. Rather, our results indicate that Seguro Popular has the biggest impact on coverage of antihypertensive treatment when the clinician to patient ratio is higher.

\section{Strengths and limitations of study}

This study makes two important contributions to the literature. Building on the recent literature about Seguro Popular, ${ }^{91938}$ we explored the effect of demand and supply related factors on coverage of antihypertensive treatment in Mexico. The consideration of health professional supply is important owing to the non-random roll-out of Seguro Popular, which presents challenges to isolating the independent effect of the programme on coverage of antihypertensive treatment. Secondly, our study highlights the importance of a high supply of health professionals in areas with Seguro Popular.

The research does, however, have several limitations. Firstly, our analysis was cross sectional, limiting our ability to estimate causal effects. In particular our finding of a clear gradation in rates of treatment and control in the Mexican population-highest among people with social security, followed by people insured through Seguro Popular, and lowest among uninsured people - suggests that Seguro Popular is having a positive effect on health. It could also be the case that insurance status is a marker for people with healthier outcomes. Longitudinal data are necessary to eliminate the possibility of reverse causality. Secondly, in our model for supply of health professionals we included only doctors classified under general or internal medicine and nurses classified as generalists. It is possible that study participants received antihypertensive treatment from other types of providers. It is also possible that our measure of health professional supply was confounded by broader influences on health. In addition, by combining the number of doctors and number of nurses per 1000 population into one measure, given that they were highly correlated, it is difficult to interpret precisely our finding of 


\section{WHAT IS ALREADY KNOWN ON THIS TOPIC}

Coverage of antihypertensive treatment requires affordability and an adequate supply of health professionals

Concerns exist that areas with a low supply of health professionals may experience a reduced impact of Seguro Popular-the programme to expand health insurance to all uninsured households in Mexico—on coverage of antihypertensive treatment

\section{WHAT THIS STUDY ADDS}

Seguro Popular is positively and significantly associated with coverage of antihypertensive treatment, particularly in areas with a high supply of health professionals

a significant interaction between supply of health professionals and insurance status. Thirdly, the overall impact of Seguro Popular may be different than our models suggest. The impact could be smaller because we estimated the effect on the basis of areas where supply of health professionals is relatively high and people insured through Seguro Popular are relatively sicker, owing to the preferential roll-out of the programme. Our analysis provides an estimate of the immediate impact of Seguro Popular rather than its long term effects. Over time the effect may be diminished as Seguro Popular is expanded to areas with healthier eligible populations and lower health professional supply. We may have underestimated Seguro Popular's impact because of our rigorous definition of controlled blood pressure and because of physician migration before data collection in 2005. Recent evidence suggests that the number of doctors and nurses per 1000 population providing health care through Seguro Popular increased from 2001 to $2005 .^{19}$ Therefore the observed effect of health professional supply on coverage of antihypertensive treatment may be reduced. Fourthly, the sample size for people aged 80 or more is relatively small, making it difficult to generalise the results to that subgroup. Finally, it is possible that our estimate of the impact of Seguro Popular on antihypertensive treatment captured some of the effect of Mexico's national hypertension programme if the impact of the national programme is greater for those insured through Seguro Popular.

The results from this study suggest the need for more research. The higher rate of antihypertensive treatment among people with social security compared with those eligible for insurance through Seguro Popular suggests the need for more studies to understand the disparity in treatment by insurance status. The low prevalence of hypertension control we observed among all Mexican adults suggests inadequate treatment (for example, ineffective drugs, inadequate dosing) or non-adherence to therapy. More longitudinal studies at patient level are needed to understand which of these mechanisms is more culpable. Also, future studies should consider whether the long term impact of Seguro Popular will differentially affect coverage of antihypertensive treatment and coverage of antihypertensive treatment with blood pressure control. In addition, given that effective control of hypertension partly depends on adequate management by health professionals, it will also be important to better understand how Seguro Popular affects coverage of antihypertensive treatment in areas with greater variation in health professional supply. Finally, other factors may help improve the control of blood pressure, such as an improved economy, declining costs of drugs, increased availability of drugs in poor areas, and patient education. Therefore, interesting research for the future would examine additional factors associated with blood pressure control among the people eligible for insurance through Seguro Popular.

\section{Conclusions}

Our findings suggest that Seguro Popular is having a positive impact on the coverage of antihypertensive treatment in Mexico, particularly in those areas with a high concentration of health professionals. Yet coverage rates of antihypertensive treatment with blood pressure control remain low. As Seguro Popular continues to expand, efforts should be made to understand the factors associated with uncontrolled hypertension in Mexico. Attention should also be focused on providing insurance and improving the volume of health professionals in areas where supply is limited. The success of Seguro Popular should serve as a positive example to other developing countries looking to create an entitlement for uninsured people.

We thank Michael Law, Emmanuela Gakidou, Goodarz Danaei, Gretchen Stevens, and Majid Ezzati for help with the analysis, and the Secretaría de Salud, who created the datasets used in this study.

Contributors: SNB, DMC, AA, and CJLM conceived the study and developed the hypotheses. SNB analysed the data. All authors contributed to the interpretation of study findings. SNB drafted the manuscript and all authors contributed to the final draft. SNB is the guarantor.

Funding: Harvard Graduate School of Arts and Sciences dissertation completion fellowship.

Competing interests: None declared

Ethical approval: Not required.

1 Allison DB, Fontaine KR, Manson JE, Stevens J, Vanltallie TB. Annual deaths attributable to obesity in the United States. JAMA 1999;282:1530-8.

2 He J, Whelton PK. Elevated systolic blood pressure and risk of cardiovascular and renal disease: overview of evidence from observational epidemiologic studies and randomized controlled trials. Am Heart / 1999;138(3):S211-9.

3 MacMahon S, Peto R, Cutler J, Collins R, Sorlie P, Neaton J, et al. Blood pressure, stroke, and coronary heart disease. Part 1, prolonged differences in blood pressure: prospective observational studies corrected for the regression dilution bias. Lancet 1990;335:765-74.

4 World Health Organization. Mortality country fact sheet 2006: Mexico 2006. Geneva: WHO.

5 Arredondo A, Zuniga A. Epidemiologic changes and economic burden of hypertension in Latin America: evidence from Mexico. Am J Hypertens 2006;19(6):553-9.

6 Neal B, MacMahon S, Chapman N, Blood Pressure Lowering Treatment Trialists' Collaboration. Effects of ACE inhibitors, calcium antagonists, and other blood-pressure-lowering drugs: results of prospectively designed overviews of randomised trials. Blood Pressure Lowering Treatment Trialists' Collaboration. Lancet 2000;356:1955-64.

7 Whelton PK, HE J. Blood pressure reduction. In: Hennekens $\mathrm{CH}$, Buring JE, Manson JE, Ridker PM, eds. Clinical trials in cardiovascular disease. Philadelphia: WB Saunders, 1999:341-59.

8 Chobanian AV, Bakris GL, Black HR, Cushman WC, Green LA, Izzo JL Jr, et al. Seventh report of the Joint National Committee on Prevention, Detection, Evaluation, and Treatment of High Blood Pressure. Hypertension 2007;42:1206-52. 
9 Lozano R, Soliz P, Gakidou E, Abbott-Klafter J, Feehan DM, Vidal C, et al. Benchmarking of performance of Mexican states with effective coverage. Lancet 2006;368:1729-41.

10 Nigenda G. The regional distribution of doctors in Mexico, 19301990: a policy assessment. Health Policy 1997;39:107-22.

11 He J, Muntner P, Roccella EJ, Streiffer RH, Whelton PK. Factors associated with hypertension control in the general population of the United States. Arch Intern Med 2002;162(9):1051-8.

12 Huttin C, Moeller JE, Stafford RS. Patterns and costs for hypertension treatment in the United States: clinical, lifestyle and socioeconomic predictors from the 1987 National Medical Expenditures Survey. Clin Drug Investig 2000;20:181-95.

13 Levine DM. Adherence to antihypertensive therapy. In: Izzo JL, Black HR, eds. Hypertension primer from the Council on High Blood Pressure Research. Dallas: American Heart Association, 1993:291-3.

14 Moy E, Bartman BA, Weir MR. Access to hypertensive care. Effects of income, insurance, and source of care. Arch Intern Med 1995;155:1497-502

15 Shea S, Misra D, Ehrlich MH, Field L, Francis CK. Predisposing factors for severe, uncontrolled hypertension in an inner-city minority population. N Engl J Med 1992;327:776-81.

16 Newhouse JP. Free for all? Lessons from the RAND health insurance experiment. Cambridge: Harvard University Press, 1993.

17 Comisión Nacional de Protección Social en Salud. Catálogo universal de servicios esenciales. Mexico City: Secretaría de Salud, 2006.

18 Secretaría de Hacienda y Crédito Público de México. Segunda Resolución de Modificaciones a la Resolución Miscelánea Fiscal para 2003. Diario Oficial de la Federación. www.dof.gob.mx/2003/mayo/ dof 15-05-2003.pdf.

19 Gakidou E, Lozano R, González-Pier E, Abbott-Klafter J, Barofsky J, Bryson-Cahn C, et al. Assessing the effect of the 2001-06 Mexican health reform: an interim report card. Lancet 2006;368:1920-35.

20 Shi L, Starfield B. The effect of primary care physician supply and income inequality on mortality among blacks and whites in US metropolitan areas. Am J Public Health 2001;91:1246-50.

21 Shi L, Macinko J, Starfield B, Xu J, Politzer R. Primary care, income inequality, and stroke mortality in the United States: a longitudinal analysis, 1985-1995. Stroke 2003;34:1958-64.

22 Perrin JM, Valvona J. Does increased physician supply affect quality of care? Health Affairs 1986;5(4):63-72.

23 Needleman J, Buerhaus P, Mattke S, Stewart M, Zelevinsky K. Nursestaffing levels and the quality of care in hospitals. $N$ Engl J Med 2002;346:1715-22.

24 Laditka JN, Laditka SB, Probst JC. More may be better: evidence of a negative relationship between physician supply and hospitalization for ambulatory care sensitive conditions. Health Serv Res 2005;40 (4):1148-66.

25 General Accounting Office. Nurse home expenditure and quality. Washington DC: GAO, 2002.

26 Ferrante JM, Gonzalez EC, Pal N, Roetzheim RG. Effects of physician supply on early detection of breast cancer. J Am Board Fam Pract 2000;13(6):408-14.

27 Anand S, Barnighausen T. Human resources and health outcomes: cross-country econometric study. Lancet 2004;364:1603-9.

28 Shi L, Macinko J, Starfield B, Wulu J, Regan J, Politzer R. The relationship between primary care, income inequality, and mortality in US States, 1980-1995. J Am Board Fam Pract 2003;16(5):412-22.

29 Secretaría de Salud. Salud Mexico 2004: información para la rendición de cuentas. Mexico City: Secretaría de Salud, 2004. Report No. 123.

30 Secretaría de Salud, Instituto Nacional de Salud Pública. Encuesta Nacional de Salud y Nutrición 2005 (ENSANut) 2006.

31 Whitworth JA, World Health Organization, International Society of Hypertension Writing Group. 2003 World Health Organization (WHO)/International Society of Hypertension (ISH) statement on management of hypertension. J Hypertens 2003;21:1983-92.

32 Ministry of Health. Subsistema de Information de Equipamiento, Recursos Humanos e Infraestructura para la Atención de la Salud (SINERHIAS) 2005.

33 Rosenbaum PR, Rubin DB. Reducing bias in observational studies using subclassification on the propensity score. J Am Stat Ass 1984;79:516-24.

34 Tomz M, Wittenberg J, King G. Clarify: software for interpreting and presenting statistical results. J Stat Software 2003;8:1-15.

35 Secretaría de Salud. Sistema de Protección Social en Salud. Elementos conceptuales, financieros y operativos. Mexico City: Secretaría de Salud, 2005.

36 World Bank. World development indicators 2006. [CD-ROM] Washington, DC: World Bank, 2006.

37 Hajjar I, Kotchen TA. Trends in prevalence, awareness, treatment, and control of hypertension in the United States, 1988-2000. JAMA 2003;290:199-206.

38 Knaul FM, Arreola-Ornelas H, Mendez-Carniado O, Bryson-Cahn C, Barofsky J, Maguire R, et al. Evidence is good for your health system: policy reform to remedy catastrophic and impoverishing health spending in Mexico. Lancet 2006;368:1828-41.

Accepted: 18 September 2007 